\title{
A case study of interior booming noise control in an HEV
}

\author{
Meng Yang ${ }^{1, a}$, Tonghang Zhao ${ }^{1,2}$, Yang Liu ${ }^{1}$, Xining Liu ${ }^{1}$ and Hangsheng $\mathrm{Hou}^{1,2}$ \\ ${ }^{1}$ Research \& Development Center, China FAW Co. Ltd., Changchun, China 130011 \\ ${ }^{2}$ State Key Laboratory of Comprehensive Technology on Automobile Vibration and Noise \& Safety Control, \\ Changchun, China 130011
}

\begin{abstract}
An interior booming noise issue occurred during a development stage of an HEV program. Based on the noise generation mechanism, the root cause analyses were carried out. It is found that the interior booming noise was mainly induced by the excessive second order noise from the exhaust tail pipe. The effort was focused on the noise source reduction. Using acoustic simulation and parameter optimization, a Helmholtz resonator was designed and proposed. The measured results based on the proposed design showed that the interior sound pressure peak level responsible for the booming noise sensation was reduced significantly. The effectiveness of the proposed design was validated by vehicle testing and subjective evaluations.
\end{abstract}

Keywords: HEV, booming, exhaust noise, low-frequency noise control.

\section{Introduction}

For the development of HEV programs nowadays, common practice for most OEMs is to carry over the body and chassis design from the corresponding conventional ICE vehicle programs to achieve faster time-to-market and reduce development cost. But, compared with conventional vehicles, HEVs have additional systems such as the driving motor, power battery, DCDC and other necessary hybrid components. These added components result in a $10 \%$ to $15 \%$ increase of the total vehicle weight. However, the hard points of the body structure, the suspension stiffness and other important design parameters basically remain unchanged. Therefore, under the same on-road driving conditions, the vibration and noise issues for HEVs would potentially be more serious and complicated than those for their conventional counterparts, especially in the middle and high speed range of the driving motor. Since the output power of a driving motor is fixed, the higher the speed, the smaller the output torque delivered by the driving motor. This smaller output torque, coupled with the increased vehicle mass, leads to a higher load and burden for the hybrid power system. Thus it is likely to cause serious vehicle NVH problems.

In this paper, based on an HEV that incorporates a driving motor and a 4-cylinder gasoline engine, the interior booming noise during acceleration encountered in a development process is described and the effort in search of its resolution is explained. The effectiveness of the proposed countermeasure is manifested by the comparison of the vehicle interior sound pressure level before and after the implementation of the proposed design.

${ }^{a}$ Corresponding author : yangmeng@rdc.faw.com.cn 


\section{Case study}

\subsection{Problem description}

During a road NVH evaluation of an HEV prototype, a booming noise issue was identified when accelerating in certain speed ranges. Such an uncomfortable experience is especially serious in the back seat. The sensation of pressure pulsation on the ear drum makes the rear occupant extremely uncomfortable.

A noise measurement test was carried out on a chassis roll dynamometer in a semi-anechoic room to identify the root cause. The measured points were set up at the left ear of the right rear seat passenger. Using the LAN-XI 50 channel noise acquisition equipment made by B\&K, the measured sound pressure level result is displayed in Fig. 1. From the figure, it is seen that there are two pronounced peaks, one around vehicle speed of $33 \mathrm{kph}$ and the other around $74 \mathrm{kph}$. The noise peak level $\Delta_{2}$ around $74 \mathrm{kph}$ is greater than that $\left(\Delta_{1}\right)$ around $33 \mathrm{kph}$, which indicates that the higher the vehicle speed, the worse the booming noise level. This outcome is consistent with the subjective observations under on-road driving conditions. Since the speed $74 \mathrm{kph}$ falls into a normal on-road driving range, it is an urgent priority to resolve this issue.

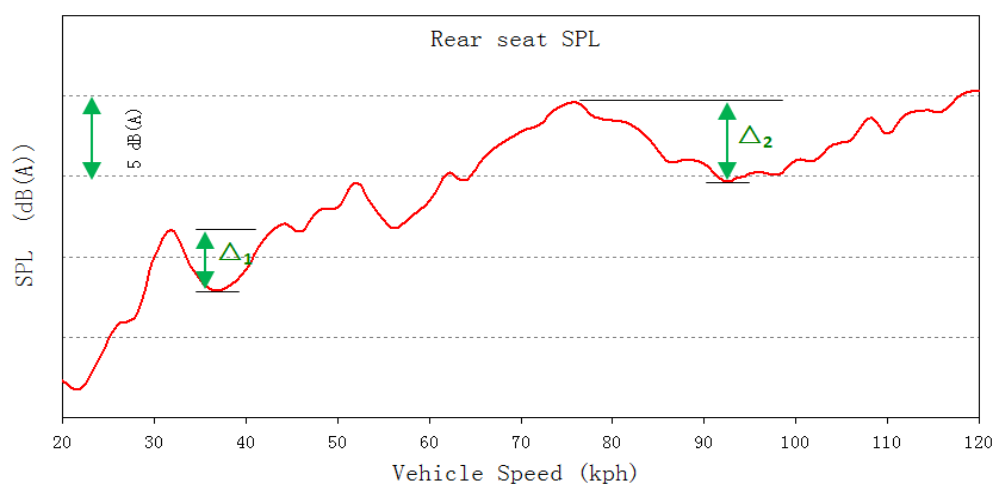

Figure 1. The measured rear seat noise level in the baseline vehicle during acceleration.

\subsection{Problem diagnostics}

The booming noise issue occurs around $33 \mathrm{kph}$ and $74 \mathrm{kph}$. After analyzing the TCU shift control strategy for vehicle accelerating operation, it reveals that the speed $33 \mathrm{kph}$ uses Gear 3 while the speed $74 \mathrm{kph}$ is in Gear 6. By further examining the gear ratio, the engine speed is found to be in the vicinity of $1750 \mathrm{rpm}$ for both $33 \mathrm{kph}$ and $74 \mathrm{kph}$ vehicle speeds, around which the booming noise issue surfaces. The frequency of the issue is about $58 \mathrm{~Hz}$, which corresponds to the second order engine excitation at $1750 \mathrm{rpm}$, and they are related by the mathematical expression $1750 / 60 * 2=58.3 \mathrm{~Hz}$. The guesstimate was that the booming noise is induced by the engine excitation, intake noise or exhaust noise.

The vehicle at issue is a rear drive type with the north-south engine architecture. In the meantime, a driving motor is configured between the engine and transmission. This leads to a situation that the transmission mount has to be located further rearward compared to its conventional counterpart. This may result in a different transmission mount performance. In light of previous conventional vehicle development experiences, the possible causes to produce interior booming noise are ranked in Table 1. In order to obtain a better understanding of the booming noise characteristics, noise measurements were carried out at the rear seat locations for Gear 3 and Gear 6 respectively. Figures 2 and 3 display the noise levels at the rear seat with respect to the engine speed, where the red curves represent the 
overall noise level while the dotted blue curves denote the $2^{\text {nd }}$ order noise levels. Both figures demonstrate that the $2^{\text {nd }}$ order noise is significant in the vicinity of the engine speed $1750 \mathrm{rpm}$, and in fact it contributes by far the most to the overall noise level.

Table1. Ranking of possible booming noise causes

\begin{tabular}{ll}
\hline & \multicolumn{1}{c}{ Possible cause of booming noise } \\
\hline 1 & Poor transmission mount isolation, excessive induced floor vibration \\
2 & Vibration transferred through exhaust hangers, inducing floor vibration \\
3 & Excessive tail pipe noise, transmitted into cabin \\
4 & Excessive muffler shell noise \\
\hline
\end{tabular}

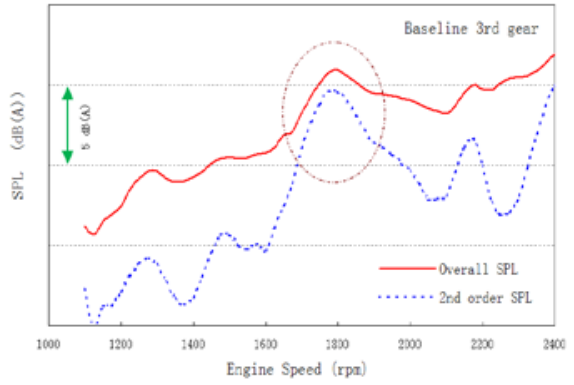

Figure 2. Rear seat noise level in $3^{\text {rd }}$ gear acceleration.

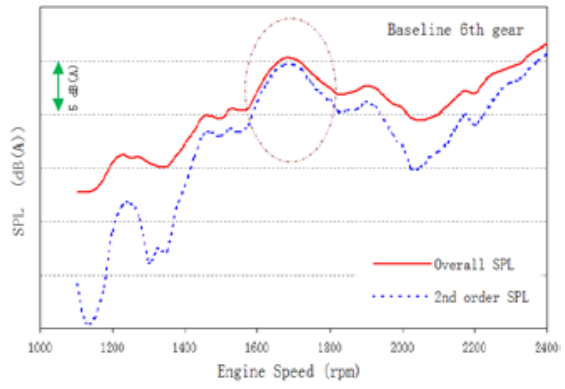

Figure 3. Rear seat noise level in 6th gear acceleration

\subsection{Root cause analysis}

A transmission mount isolation test was carried out, and the results are shown in Figures 4 and 5 . From the figures, it is apparent that the vibration amplitude is relatively small at the connection point between the transmission mount and the body. Moreover, there is no pronounced peak around the engine speed $1750 \mathrm{rpm}$. Therefore, it is concluded that the transmission mount is not a major contributor to the booming noise issue.

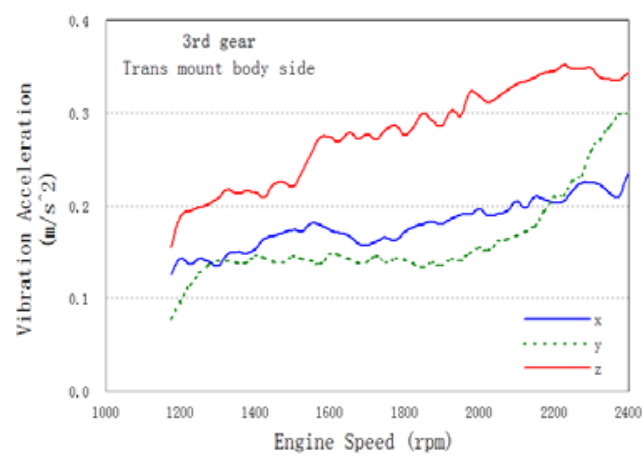

Figure 4. Transmission mount vibration in $3^{\text {rd }}$ gear acceleration.

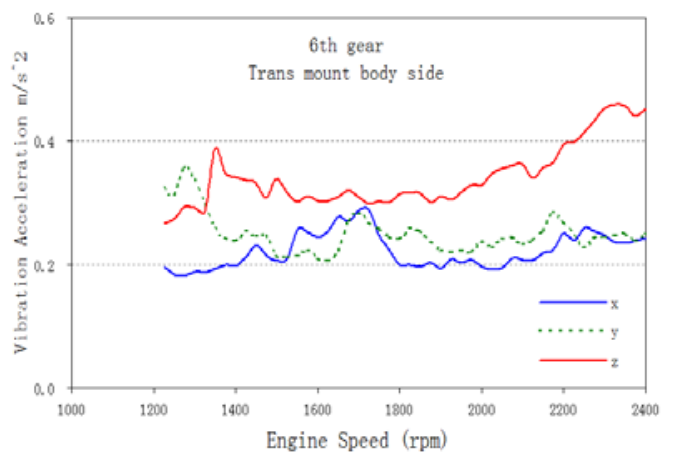

Figure 5. Transmission mount vibration in 6th gear acceleration.

All exhaust hangers were disconnected while keeping all other components intact, and the measurement tests were performed on the chassis roll dynamometer. The comparison results are shown in Figures 6 and 7. From the figures, it is obvious that the noise levels with the hangers detached are not much different from those of the baseline case. Subjective evaluations on the chassis roll dynamometer confirm that the improvement is not discernible. This concludes that the hangers are not the cause of the issue. 


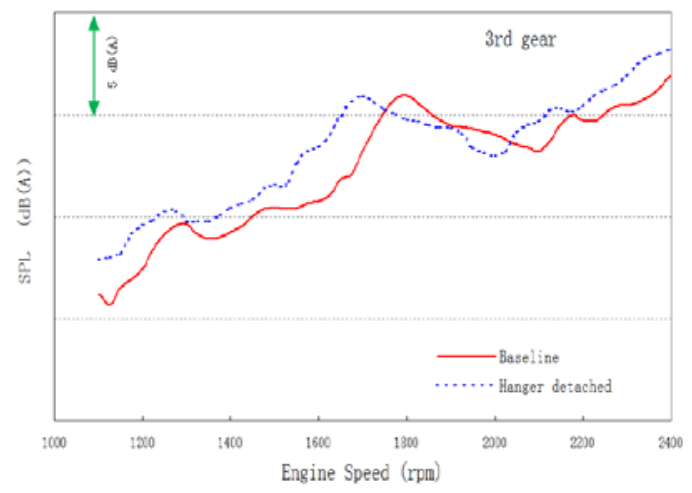

Figure 6. Noise level comparison with and without the exhaust hangers in $3^{\text {rd }}$ gear acceleration.

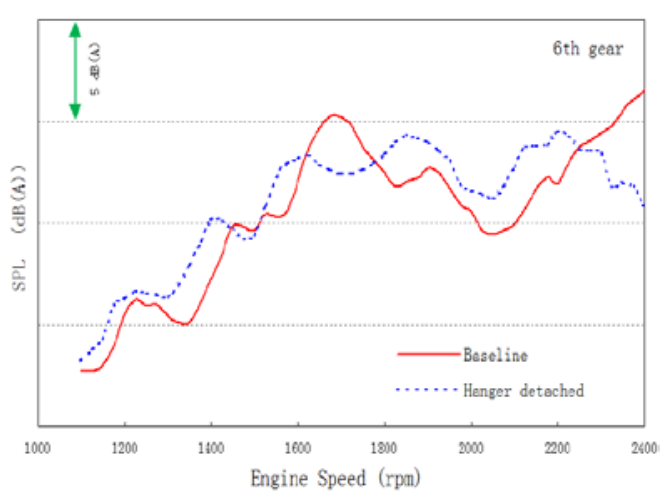

Figure 7. Noise level comparison with and without the exhaust hangers in 6th gear acceleration.

After eliminating the structure-borne noise as the root cause of the issue, the focus is on the tail pipe noise and the muffler shell noise.

To look into the influence of the tail pipe noise, a 2.5 meter long pipe was connected to the tail pipe in order to simulate the absence of the tail pipe noise. The measured results are represented by the dotted blue curves in Figures 8 and 9, where the red curves represent the baseline results for reference.

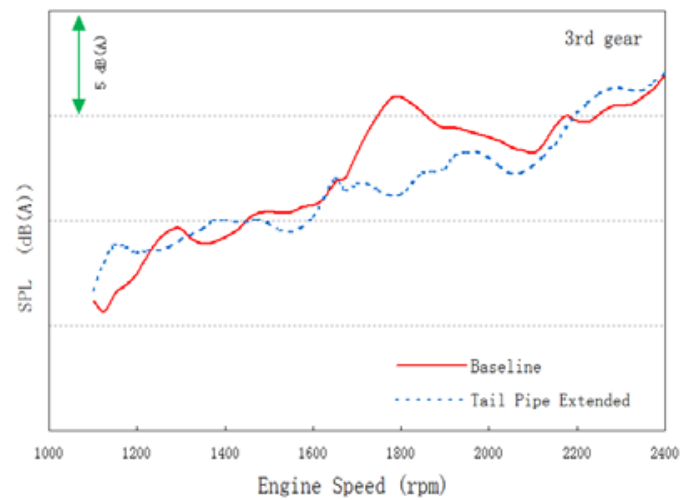

Figure 8. Noise level with extended tail pipe compared to baseline in $3^{\text {rd }}$ gear acceleration.

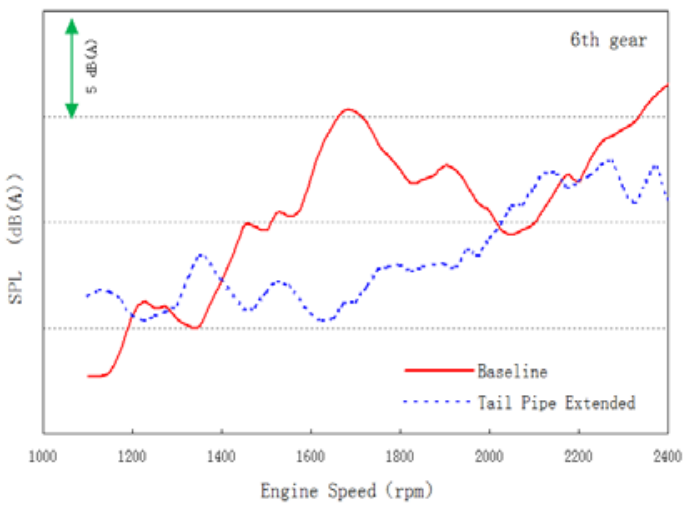

Figure 9. Noise level with extended tail pipe compared to baseline in 6th gear acceleration.

With the extended tail pipe, the interior noise level around the engine speed $1750 \mathrm{rpm}$ is reduced significantly. From Figure 8, it is seen that the maximum interior noise reduction is $5 \mathrm{~dB}(\mathrm{~A})$ in Gear 3, while in Gear 6, the maximum reduction reaches $8 \mathrm{~dB}(\mathrm{~A})$ as shown in Fig. 9.

Furthermore, the linearity of the powertrain sound, a metric of powertrain NVH refinement, is improved. The booming noise sensation in this case is minimized. It is therefore concluded that the tail pipe noise is the root cause of the booming noise issue. The outcome in Figures 8 and 9 also renders the study of muffler noise unnecessary.

\subsection{Issue resolution}

\subsubsection{Tail pipe noise reduction}

Exhaust tail pipe noise is mainly composed of pulse noise and aeroacoustic noise. The pulsating noise is induced by the periodic opening and closing of the exhaust valve which form periodic air pressure fluctuations in the exhaust pipe. 
The aeroacoustic noise is induced by the friction between the air flow in the exhaust pipe and the bent exhaust pipe wall as well as the turbulence in the exhaust gas flow. This aeroacoustic noise however is wide band in nature.

The tail pipe noise in this case has a frequency of $58.3 \mathrm{~Hz}$. It is the in-pipe low frequency noise induced by the pulsating pressure. Common practice to reduce such noise includes improving muffler internal cavity structure, perforation pattern, and increasing transmission loss.

Due to the fact that the vehicle program is already at a very late stage, a design change in muffler structure would result in a program delay. It is simply unacceptable to change the muffler design by the program management.

Fig. 10 shows the exhaust system for the vehicle in this study. It incorporates a two stage noise reduction layout involving a front muffler and a rear muffler.

In consideration of program timing, cost, package limitations and the effectiveness of the measure, it was decided that the original system should be kept intact. Therefore, a design of a Helmholtz resonator in front of the front muffler was proposed as shown in Fig. 11, with the intended center frequency of $58.3 \mathrm{~Hz}$.

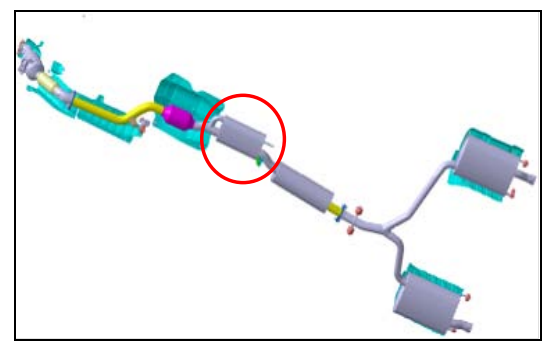

Figure 10. The baseline exhaust system.

\subsubsection{Design of Helmholtz resonator}

One of the most prominent characteristics of an exhaust system would be the high temperature. And the temperature changes drastically along the exhaust pipe. In the exhaust manifold, the temperature can reach $800^{\circ} \mathrm{C}$ or even higher, while at the tail pipe it is only about $300^{\circ} \mathrm{C}$. The speed of sound $c$ and temperature $T$ have the following relation:

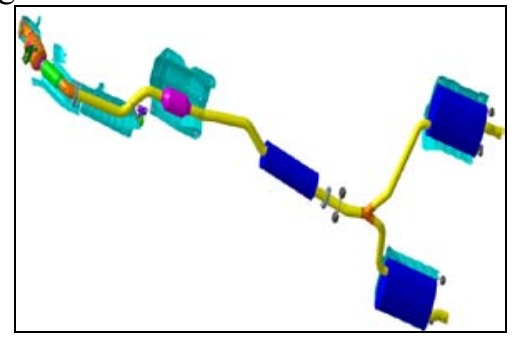

Figure 11. The proposed exhaust system with an added resonator.

$$
c \approx 20 \sqrt{273+T} .
$$

Therefore, before the resonator design, the temperature and flow velocity at the intended resonator installation location need to be obtained, and the quantities measured from testing were used as the boundary conditions when establishing the Helmholtz resonator model. As indicated in Fig. 12, the optimal geometric parameters were obtained by DOE analyses in which important parameters were variables and maximizing transmission loss around desired frequency content was the objective. 


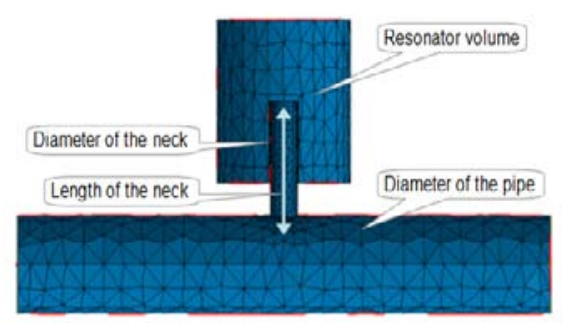

Figure12. Helmholtz resonator CAE model.

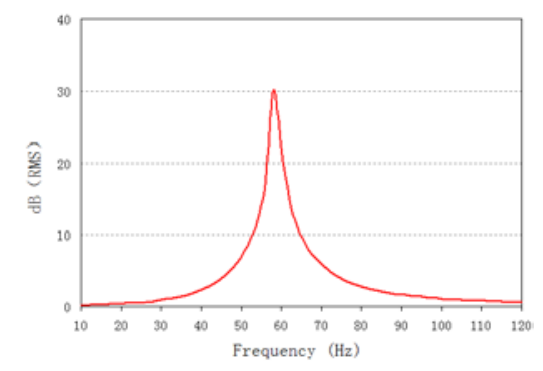

Figure 13. Transmission loss

Table 2. Helmholtz resonator parameters.

\begin{tabular}{cccc}
\hline $\mathrm{V}(\mathrm{L})$ & $\mathrm{D}(\mathrm{mm})$ & $\mathrm{L}(\mathrm{mm})$ & $\mathrm{D}(\mathrm{mm})$ \\
\hline 4.22 & 35 & 431 & 57.5 \\
\hline
\end{tabular}

There are many methods to assess the noise reduction ability of a resonator. Transmission loss $T L$ is used frequently in automotive applications:

$$
T L=10 \log \frac{W_{\text {in }}}{W_{\text {out }}}=10 \log \frac{S_{\text {in }} P_{\text {in }}^{2}}{S_{\text {out }} P_{\text {out }}^{2}}
$$

where $W_{\text {in }}, P_{\text {in }}$ and $S_{\text {in }}$ are sound power, sound pressure level and the cross-sectional area for inlet, and $W_{\text {out }}, P_{\text {out }}$ and $S_{\text {out }}$ are the same quantities at outlet.

After optimization, the parameters were obtained as listed in Table 2. The transmission loss, calculated based upon these parameters, is displayed in Fig. 13, which shows a center frequency of $58.3 \mathrm{~Hz}$, effective bandwidth of about $12 \mathrm{~Hz}$ and the peak transmission loss of $30.1 \mathrm{~dB}$.

The proposed resonator was fabricated and implemented on a prototype vehicle. The measurement was carried out again in the semi-anechoic room. The obtained results are represented by the blue dotted curves in Figs. 14 and 15, where the baseline result is represented by the red curves for comparison.

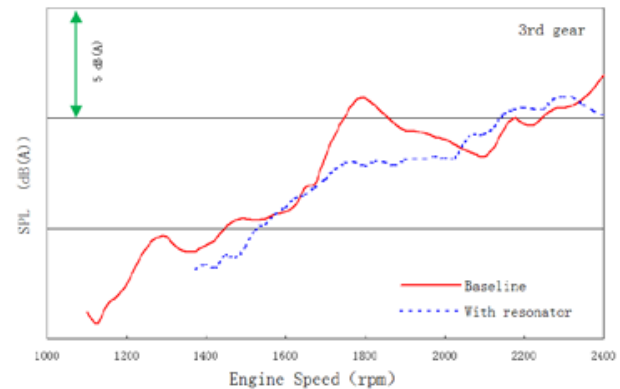

Figure14. SPL with resonator compared to baseline in $3^{\text {rd }}$ gear acceleration.

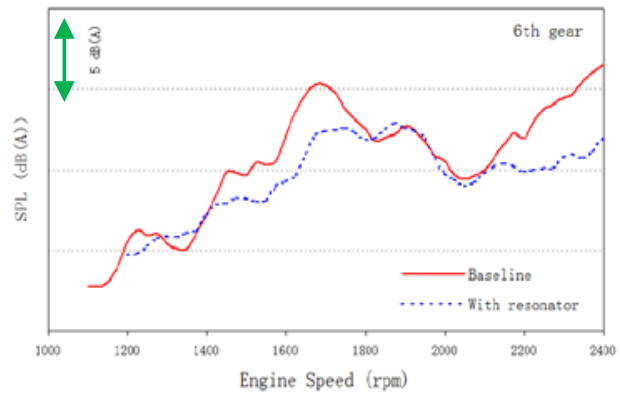

Figure 15. SPL with resonator compared to baseline in 6th gear acceleration. 
The pronounced peak basically disappeared for the proposed design around engine speed 1750 rpm in Gear 3 acceleration, and the booming noise issue is resolved in this case. In Gear 6 acceleration, Fig. 15 indicates that the sound pressure level decreases by $3 \mathrm{~dB}(\mathrm{~A})$ around $1750 \mathrm{rpm}$ with the proposed design. Although the noise peak still exists, its level is greatly reduced. Subjective evaluations indicated that the booming noise sensation is reduced noticeably.

\section{Conclusions}

In order to resolve the booming noise issue, a test analysis was carried out by analyzing the engine order content in the noise spectrum and using control variable method to zero in on the root cause of the issue. It is determined that the interior $58.3 \mathrm{~Hz}$ booming noise was induced by the $2^{\text {nd }}$ order noise at the tail pipe. By implementing a tuned resonator, the level of the noise source was greatly reduced.

Most current hybrid vehicle development efforts rely on carry-over structures such as body, chassis, intake and exhaust systems etc to shorten the development time. This practice oftentimes leads to serious NVH problems for HEVs. Therefore the risks and possible issues in vehicle attributes should be carefully assessed early, and an action plan should be in place that factors in the time and engineering resource needed to overcome the potential issues.

\section{References}

1. W. Zhang and Z.W. Cheng. The improvement of roar noise in acceleration. 2014CGNV055:1411-1415

2. T.H. Zhao, B.W. LU and Y.T. CAO, Hybrid vehicle vibration noise control technology. Journal of Jilin university (engineering science), 2012, 42(6), 1373-1377.

3. J.B. Li and H. Wang, Order analysis application in vehicle booming problem control. Automotive engineers, 2014(6), 57-59.

4. J. Pang, Vehcile body noise and vibration control, Beijing, Mechanical industry press, 2015.1.

5. Cao,Y.,Zhao,T.,Li,C.,Yang,M.,etal., "Exterior Noise Source Identification and Contribution Analyses for Electric Vehicles,"SAE Technical Paper 2016-01-1324, 2016,doi:10.4271/201601-1324.

6. J. Pang, G. Zhan and H. He, Automotive noise and vibration principle and application, Beijing Institute of Technology Press, 2006. 